\title{
Exosomal FMR1-AS1 facilitates maintaining cancer stem-like cell dynamic equilibrium via TLR7/NFKB/c-Myc signaling in female esophageal carcinoma
}

Wei $\mathrm{Li}^{1 \dagger}$, Liyuan Zhang ${ }^{2 \dagger}$, Binbin Guo ${ }^{1 \dagger}$, Jieqiong Deng ${ }^{1}$, Siqi Wu' ${ }^{1}$, Fang $\mathrm{Li}^{1}$, Yirong Wang ${ }^{1}$, Jiachun $\mathrm{Lu}^{3}$ and Yifeng Zhou ${ }^{1 *}$

\begin{abstract}
Background: Though esophageal cancer is three to four times more common among males than females worldwide, this type of cancer still ranks in the top incidence among women, even more than the female specific cancer types. The occurrence is currently attributed to extrinsic factors, including tobacco use and alcohol consumption. However, limited attention has been given to gender-specific intrinsic genetic factors, especially in female.

Methods: We re-annotated a large cohort of microarrays on 179 ESCC patients and identified female-specific differently expressed IncRNAs. The associations between FMR1-AS1 and the risk and prognosis of ESCC were examined in 206 diagnosed patients from eastern China and validated in 188 additional patients from southern China. The effects of FMR1-AS1 on the malignant phenotypes on female ESCC cells were detected in vitro and in vivo. ChIRP-MS, reporter gene assays and EMSA were conducted to identify the interaction and regulation among FMR1-AS1, TLR7 and NFKB.

Results: We found FMR1-AS1 expression is exclusively altered and closely associated with the level of $s$ XCl in female ESCC patients, and its overexpression may correlate to poor clinical outcome. ChIRP-MS data indicate that FMR1-AS1 could be packaged into exosomes and released into tumor microenvironment. Functional studies demonstrated that FMR1-AS1 could bind to endosomal toll-like receptor 7 (TLR7) and activate downstream TLR7-NFKB signaling, promoting the c-Myc expression, thus inducing ESCC cell proliferation, anti-apoptosis and invasion ability. Exosome incubation and Co-xenograft assay indicate that FMR1-AS1 exosomes may secreted from ESCC CSCS, transferring stemness phenotypes to recipient non-CSCS in tumor microenvironment. Furthermore, we also found a correlation between the serum levels of FMR1-AS1 and the overall survival (OS) of the female ESCC patients.
\end{abstract}

Conclusions: Our results highlighted exosomal FMR1-AS1 in maintaining CSC dynamic interconversion state through the mechanism of activating TLR7-NFKB signaling, upregulating c-Myc level in recipient cells, which may be taken as an attractive target approach for advancing current precision cancer therapeutics in female patients.

Keywords: ESCC, IncRNA, Exosome, CSC, TLR7, NFKB, c-Myc

\footnotetext{
* Correspondence: zhouyifeng@suda.edu.cn

'Wei Li, Liyuan Zhang and Binbin Guo contributed equally to this work.

${ }^{1}$ Department of Genetics, Medical College of Soochow University, Suzhou

215123, China

Full list of author information is available at the end of the article
}

(c) The Author(s). 2019 Open Access This article is distributed under the terms of the Creative Commons Attribution 4.0 International License (http://creativecommons.org/licenses/by/4.0/), which permits unrestricted use, distribution, and reproduction in any medium, provided you give appropriate credit to the original author(s) and the source, provide a link to the Creative Commons license, and indicate if changes were made. The Creative Commons Public Domain Dedication waiver (http://creativecommons.org/publicdomain/zero/1.0/) applies to the data made available in this article, unless otherwise stated. 


\section{Background}

Esophageal squamous cell carcinoma (ESCC), a predominant histologic type of esophageal carcinoma, is one of the most invasive human cancer in the world and the second most common cancer in China [1]. Though, esophageal cancer is three to four times more common among men than among women, this type of cancer still ranks in the top- 6 incidence among women, even more than the female specific cancer types. Current epidemiologic studies often focus on the extrinsic environmental factors that may play a role in the observed sex disparity in ESCC incidence, such as tobacco use and alcohol consumption. However, the intrinsic molecular and genetic factors underlaying the incidence of ESCC based on gender remain largely unknown, especially in female patients. The sex-associated chromosome X carries around 2000 genes and makes up about 5\% of the total DNA in women and $2.5 \%$ in men, including a large number of non-coding RNAs. LncRNAs are involved in multilevel regulation of gene expression, including transcriptional regulation by recruitment of chromatin-modifying complexes [2] and post-transcriptional regulation by interaction with miRNAs, mRNAs, or proteins [3]. LncRNAs could modulate numerous hallmarks of cancer, including proliferation [4], apoptosis [5], metastasis [6], and metabolism [7]. However, the roles of X-associated lncRNAs in female specific ESCC are unexplored.

Exosomes are generated inside multivesicular endosomes [8] and can be secreted from multiple types of cells and participate in intercellular communication by transmitting intracellular cargoes, such as proteins and nucleic acids [9]. It has been reported that numerous lncRNAs could be transferred between cancer cells, transmit signals and phenotypes via exosomes derived from human cervical and breast carcinomas [10, 11]. However, functions of exosomal lncRNAs derived from ESCC cells are still unknown. Emerging evidence revealed that the molecular cross-talking between CSCs and non-CSCs in tumour microenvironment plays a critical role in CSCs-non-CSCs dynamic equilibrium [12]. CSCs are not a static cell population with the capacity of initiating tumor through asymmetric cell division, but a cell population in highly dynamic equilibrium state, which could be maintained through the dedifferentiation of matured cancer cells [13, 14]. CSCs and non-CSCs are not in a motionless but in a dynamic equilibrium state: CSCs differentiate into non-CSCs under some circumstances, and non-CSCs could dedifferentiate into CSCs [12]. However, the cellular and molecular mechanisms of interconversion between differentiated non-CSCs and CSCs are still in the mist. Exosomes secreted by tumor cells provide a physical means to transfer a variety of intracellular molecules into the surrounding cells, where these molecules exert regulatory effects, and may serve as important molecular information carriers to communicate with CSCs, non-CSCs and other cells in tumor microenvironment $[15,16]$. Tumorcell-derived exosomes are found in all body fluids, upon contact with target cells, they can alter phenotypic and functional attributes of recipients, reprogramming them into active contributors to tumor growth, metastasis and immunosuppression [17-19]. However, the role of exosomes, specifically exosomal lncRNAs, in the reciprocal conversion between non-CSCs and CSCs was rarely investigated.

In this study, we report the investigation on the role of FMR1-AS1 in female-specific ESCC incidence and explored the potential implications for specific diagnosis and prognosis of female ESCC patients. Our results revealed the function of exosomal FMR1-AS1 in maintaining ESCC CSC dynamic interconversion and the possible mechanism of its action, which shed light on the functional exosomal lncRNAs might be taken as attractive targets for ESCC precision therapeutics and improved the understanding how CSCs and non-CSCs cell states coexist, transmit and evolve within tumors that may futher facilitate the development of more effective therapies.

\section{Methods}

\section{Study subjects}

Two hundred six fresh ESCC tissues and paired adjacent non-cancerous tissue samples were obtained from the patients in eastern China who underwent tylectomies at the Affiliate Hospitals of Soochow University (Suzhou). One hundred eighty-eight fresh ESCC tissues were collected from the patients at the Cancer Hospitals affiliated with Guangzhou Medical University in southern China and were used for further validation. None of the patients received anti-cancer treatment before surgery, including chemotherapy or radiotherapy. The clinical characteristics of the patients are listed in Additional file 1: Table S1.

\section{Comprehensive identification of RNA-binding proteins by mass spectrometry (ChIRP-MS)}

10-20 $15 \mathrm{~cm}$ dishes of cells were used per ChIRP-MS experiment (100million - 500million cells depending on the cell type). Cell harvesting, lysis, disruption, and ChIRP were essentially performed as previously described [20] and follow the manufacturer's instruction (Magna ChIRP, Millipore, USA). Final protein samples were size-separated in bis-tris SDS-PAGE gels (Invitrogen) for western blots and MS. The following antibodies were used in the followed western-blotting: anti-TLR7 (ab45371, Abcam), anti-hnRNPK (ab39975, Abcam), anti-PRDX1 (ab41906, Abcam), anti-PRDX2 (ab109367, Abcam), anti-ECM1 (ab126629, Abcam) and anti- $\beta$-actin (ab8227, Abcam). See Additional file 2: Materials and Methods for details. 


\section{Statistical analysis}

The accession number for the microarray data analyzed in this paper is Gene Expression Omnibus database GEO: GSE53625 and GSE70817. The ribosome profiling data were obtained from the GSE61742. The data analysis was performed using SPSS 20.0 (IBM, US). Kaplan-Meier estimate with log-rank test was used to compare patient's survival by different FMR1-AS1 expression levels. For functional analysis, results were presented as mean \pm SEM. Comparison of mean between two groups was conducted using Student's t-test, while the comparison for more than two groups was conducted using one-way ANOVA. Data in abnormal distribution were analyzed by non-parametric test. Statistical significance was two-tailed and set at $P<0.05$.

\section{Results}

FMR1-AS1 highly expressed in ESCC tissues and indicate a poor prognosis in female patients

We first compared the IncRNA expression profiles of 179 pairs ESCC tissues and its adjacent normal tissues. Unsupervised hierarchical clustering was used to divide the ESCC tissues into female and male groups. In total, 40,410 differently expressed probes with adjusted $P<0.01$ were selected from the male group (146 patients), and 18,482 differently expressed probes were selected from the female group (33 patients, adj. $P<0.01$ ). One hundred forty two probes differently expressed in the female ESCC patients were not included in those of male patients (Fig. 1a-c). Among these 142 differently expressed genes, we identified 12 lncRNAs (Fig. 1d). The only X chromosome lncRNA, FMR1-AS1, comes into our notice. In our patient samples expression measurement, FMR1-AS1 was significantly higher $(\sim 2.65$-fold, $P<0.001)$ in the tumor tissues than in the adjacent non-neoplastic tissues in female patients from Suzhou $(n=206)$. Consistent with Suzhou samples, the FMR1-AS1 level was also notably higher ( 2.3-fold, $P<0.001)$ in female tumor tissues than in adjacent non-neoplastic tissues from Guangzhou $(n=188)$ (Fig. 1e). However, no significant differences found in male ESCC samples from both area (Suzhou: 192, Guangzhou: 168) (Additional file 3: Figure S1a-c and Additional file 4).

Next, we determined the correlation between the expression levels of FMR1-AS1 and the overall survival (OS) of the female ESCC patients. The ESCC patients were classified into high and low FMR1-AS1 groups, according to the medium expression level of FMR1-AS1 among female ESCC tissues. A log-rank test and Kaplan-Meier survival curves in the discovery, validation and the pooled sets were used to compare the two FMR1-AS1 groups. We found that female patients from the discovery set (Suzhou: 206) in the high FMR1-AS1 subgroup had a lower OS than those in the low FMR1-AS1 subgroup $(\mathrm{HR}=1.618 ; 95 \% \mathrm{CI}=1.117-2.345$;
$P=0.009$ ). And this result was confirmed in the validation set (Guangzhou: $188, \mathrm{HR}=1.768$; $95 \% \mathrm{CI}=1.189$ 2.631; $P=0.0031)$ and the pooled set $(\mathrm{HR}=1.679$; $95 \% \mathrm{CI}=1.28-2.202 ; P=0.0001)$, the high FMR1-AS1 group showed a lower OS of female ESCC patients (Fig. 1f, Additional file 3: Figure S1d and Additional file 4). The sequence of full-length FMR1-AS1 has been documented in previous studies that use rapid amplification of cDNA ends (RACE) [21]. We also used northern blot to verify the expected size of FMR1-AS1 in the total RNA of two pairs of human ESCC tissue samples (Fig. 1g).

\section{FMR1-AS1 transcriptionally regulated by NFKB and associated with skewed $\mathrm{X}$-chromosome inactivation in female ESCC patients}

To further verify the coding potential of FMR1-AS1, we re-analyzed a dataset of human lymphoblastoid cell ribosome sequencing profiling and measured the ribosome occupancy level at the FMR1 gene locus. As expected, the ribosome profiling reads are highly concentrated within the coding region of FMR1 gene rather than FMR1-AS1 (Fig. 2a). In addition, the PhyloCSF score is -101.3062, lower than the cutoff 60.7876, which further supports the finding that FMR1-AS1 has no protein-coding potential. Confocal microscopy for fluorescent in situ hybridization (FISH) showed that FMR1-AS1 located primarily in the cytoplasm (Fig. 2b), which was confirmed by $\mathrm{qPCR}$ in nuclear/cytoplasm fractionation (Fig. 2c), may exert its biological function in the cytoplasm of ESCC cells.

To investigate upstream regulation on FMR1-AS1, we searched the TFBS motifs in FMR1-AS1 promotor region through TRANSFAC and JASPAR matrix using LASAGNA-Search 2.0. Interestingly, we found several evolutionarily conserved NFkB-binding motifs within the promoter of FMR1-AS1(Additional file 5: Figure S2a and Additional file 4). As core factors of NFkB with transcription activity, p50 and p65 showed significant increases at the specific sites within the promoter of FMR1-AS1, while no enrichment was shown at the negative control sites that contain irrelevant regions (Fig. 2d). Sc-3060 and JSH-23, two inhibitors for $\mathrm{NFKB}$ nuclear translocation, abrogated the TNF- $\alpha$-induced FMR1-AS1 upregulation in female ESCC cells (Fig. 2e, Additional file 5: Figure S2b and Additional file 4). Next, we cloned the proximal promoter region of FMR1-AS1 to construct reporter plasmids (pGL3-FMR1-AS1) and performed luciferase assays in ESCC cells or cells treated with two inhibitors of NFkB, Sc-3060 and JSH-23. As illustrated in Fig. 2f, compared to the control cells, the NFKB-inhibited cells had a significantly lower luciferase activity.

FMR1-AS1 is antisense to the CGG repeat region of the FMR1 gene in the same locus and have been 


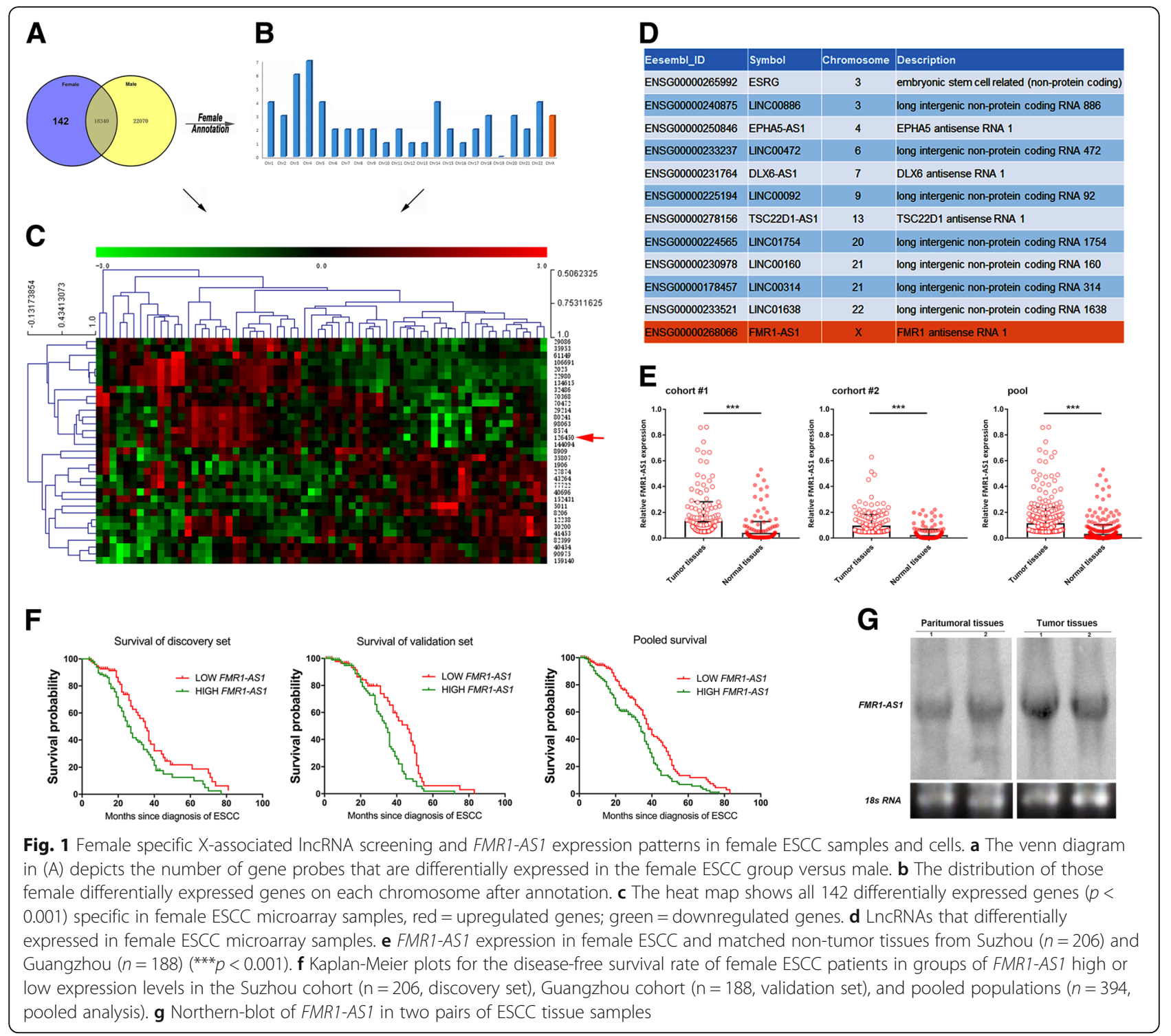

reported to be silenced by the repeat expansion [22]. This CGG repeat length of FMR1 locus have been reported a role in determining $\mathrm{X}$-chromosome inactivation [23]. While sXCI also have been considered as a predisposing factor for the early development of esophageal carcinoma [24], it is biologically reasonable to expect a possible relationship between the female ESCC sXCI and the FMR1-AS1 expression.

Both $C R \geq 3$ and $C R \geq 10$ were used as the criteria of sXCI in the subjects (Fig. 2g, Additional file 5: Figure S2c and Additional file 4). In total of 394. ESCC samples, the heterozygosity frequency of AR is about $90.86 \%$ and 358 ESCC patients were used to detect sXCI. Interestingly, more sXCI patients were found in the high FMR1-AS1 expression group than in the low FMR1-AS1 expression group $(C R \geq 3: 48.60 \%$ versus $25.14 \%$; $C R \geq 10$ : $17.88 \%$ versus $5.03 \%$ ) (Fig. $2 \mathrm{~h}$, i). Furthermore, the sXCI patients showed a significantly higher expression level of FMR1-AS1 than the non-sXCI patients (Fig. 2j).

For females, most of expression of $\mathrm{X}$-linked genes are regulated by $\mathrm{XCI}$, which occurs during fetal period and determined by XIST and its antisense, TSIX. Thus, we measured the expression levels of XIST, TSIX and FMR1-AS1 in ESCC tissues to determine whether FMR1-AS1 had a correlation with XIST or TSIX. The results suggesting that the TSIX expression may also influence FMR1-AS1 in female ESCC (Fig. 2k, l).

\section{Effects of ectopic FMR1-AS1 expression on ESCC cell malignant phenotypes}

We next examined the effects of FMR1-AS1 on female ESCC cell phenotypes (Additional file 6: Figure S3a and Additional file 4). The results showed that overexpression of FMR1-AS1 in ECA-109 and KYSE-150 


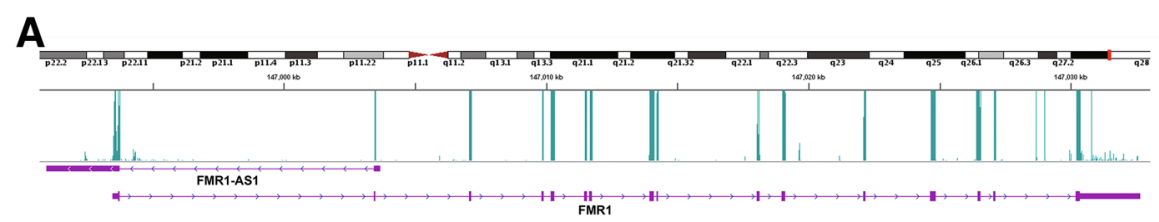

B

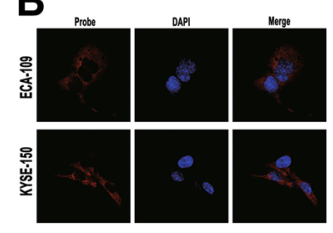

D

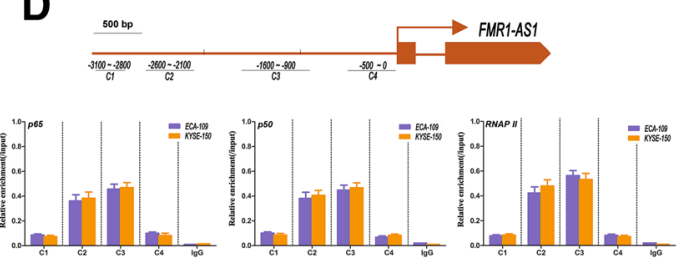

G
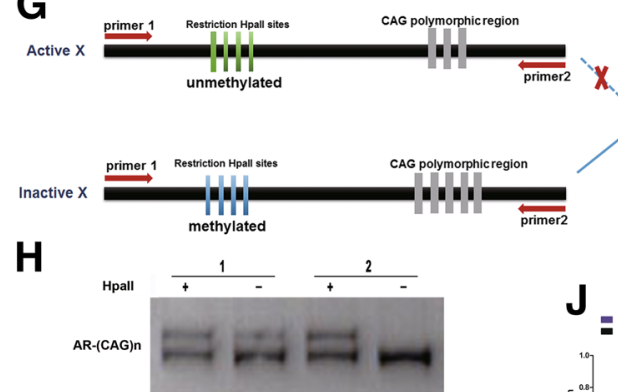

I

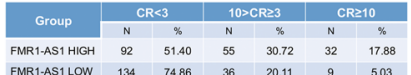

C

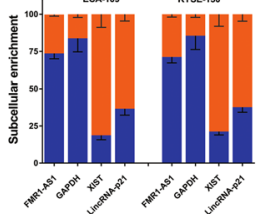

E
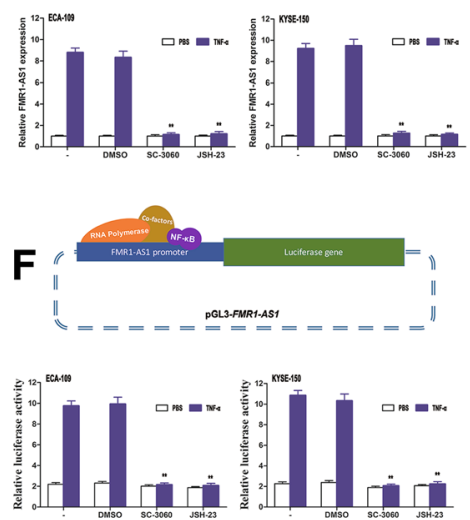

K

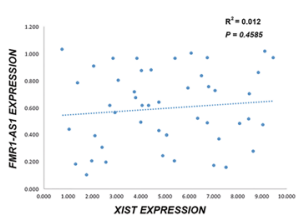

L

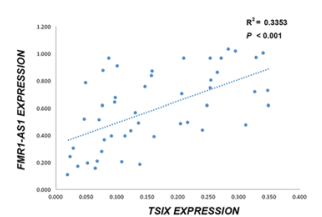

Fig. 2 Biological characterization of FMR1-AS1. a Ribosome occupancy at the FMR1 and FMR1-AS1 locus. The green peaks indicate reads density that mapped at the region. b RNA fluorescence in situ hybridization to localize FMR1-AS1. c Relative abundance of FMR1-AS1 transcript in cytoplasm, nucleus and chromatin in female ESCC cells. GAPDH, XIST and LincRNA-p21 were used as controls respectively. d Expression of FMR1AS1 in ESCC cells induced by TNF-a with or without NF-kB inhibition by SC-3060 or JSH-23 (mean \pm SD, $n=5,{ }^{*} p<0.01$ ). e Chromatin immunoprecipitation showing p65, p50 and RNAP II occupancy at the FMR1-AS1 locus in ESCC cells. Locations of amplicons (C1-C4) are indicated in the scheme above. Values represent the enrichment of bound protein fractions relative to input (mean $\pm S D, n=3$ ). $\mathbf{f}$ Luciferase reporter assay in ESCC cells induced by TNF-a with or without NF-kB inhibition by sc-3060 or JSH-23, and the reporter constructs expressing the luciferase gene under FMR1-AS1 promoter segment (mean $\pm \mathrm{SD}, \mathrm{n}=5,{ }^{*} p<0.01$ ). $\mathbf{g}, \mathbf{h} \mathrm{s} \mathrm{XCl}$ detection assays, based on Hpall digested genomic DNA PCR on the highly polymorphic CAG repeat-region of androgen receptor $(A R)$, which amplifies the undigested inactive $X$ chromosome only. i sXCI frequency in the FMR1-AS1 high/low groups of female ESCC tissues $\left(P_{X}^{2}<0.001\right)$. $\mathbf{j}$ FMR1-AS1 expression in female ESCC patients with or without $s X C I(C R \geq$ 3). $\mathbf{k}$, I Correlation analysis on the expression level of FMR1-AS1, XIST $\left(R^{2}=0.012, P<0.4585\right)$ and $T S I X\left(R^{2}=0.3353, P<0.001\right)$

substantially promoted cell proliferation, whereas the knockdown of FMR1-AS1 significantly abolished this effect (Fig. 3a). We also found that FMR1-AS1 overexpression resulted in a significant accumulation of ECA-109 and KYSE-150 cells in the G2-M phase using PI-staining and FACS sorting. No significant effects on other cell phase percentages were observed (Additional file 6: Figure S3b and Additional file 4). Interestingly, knockdown of FMR1-AS1 significantly increased cell apoptosis of ECA-109 and KYSE-150, while overexpression of FMR1-AS1 caused a modest but significant decrease of apoptosis (Fig. 3b, Additional file 6: Figure S3c and Additional file 4). We then conducted transwell and wound-healing assays, using ESCC cells with FMR1-AS1 overexpressed and knocked-down. Both transwell and wound-healing assays demonstrated that the migration capability of ECA-109 and KYSE-150 cells was significantly induced by FMR1-AS1 overexpression and 


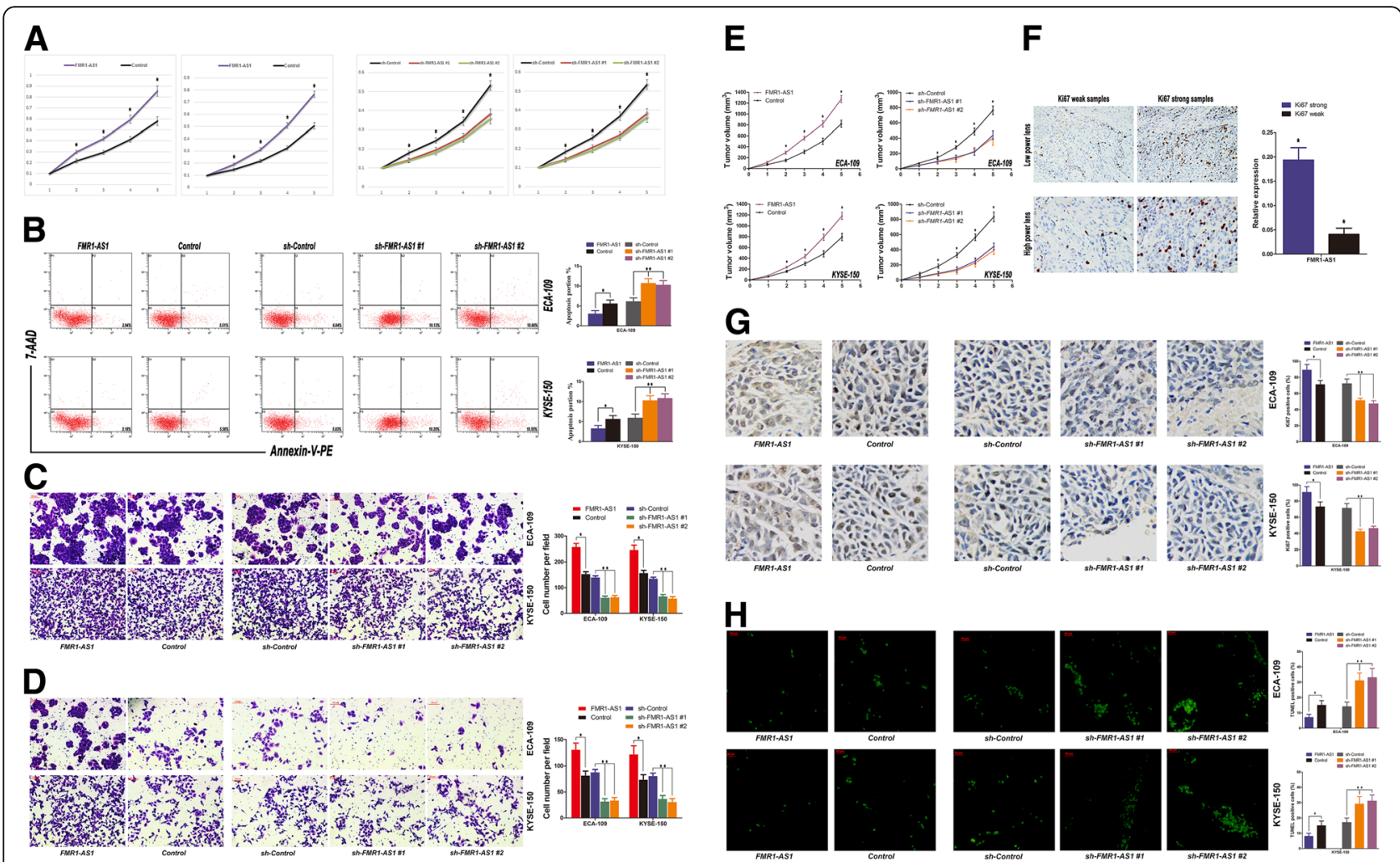

Fig. 3 Effects of ectopic FMR1-AS1 expression on female ESCC cells. a Cell proliferation assay on FMR1-AS1-upregulated, FMR1-AS1-downregulated and respective control ESCC cells using the Cell Counting Kit-8 (mean $\pm \mathrm{SD}, n=6,{ }^{*} p<0.05$ ). b Apoptosis rates on ESCC cells transfected with FMR1-AS1, Control, sh-Control, sh-FMR1-AS1 \#1 and sh-FMR1-AS1 \#2 lentiviruses, using flow cytometry (mean $\pm S D, n=6,{ }^{*} p<0.05$ ). c, d Migration and invasion of ESCC cells transfected with FMR1-AS1, Control, sh-Control, sh-FMR1-AS1 \#1 and sh-FMR1-AS1 \#2 lentiviruses. Right panel is the quantification of migrated/invaded cells (mean $\pm \mathrm{SD}, \mathrm{n}=6,{ }^{*} p<0.05$ ). e Xenograft mice subcutaneously implanted FMR1-AS1-upregulated, FMR1AS1-downregulated and respective control ESCC cells (mean $\pm \mathrm{SD}, \mathrm{n}=6,{ }^{*} p<0.05$ ). $\mathbf{f}$ Ki67 immunostaining in female ESCC samples and FMR1-AS1 expression in Ki67 strong and weak samples. $\mathbf{g}$ Ki67 immunostaining in xenograft tumors of FMR1-AS1-upregulated, FMR1-AS1-downregulated and respective control ESCC cells. $\mathbf{h}$ TUNEL staining in xenograft tumors of FMR1-AS1-upregulated, FMR1-AS1-downregulated and respective control ESCC cells

reduced by FMR1-AS1 knockdown (Fig. 3c, d, Additional file 6: Figure S3d and Additional file 4). We also used ECA-109 and KYSE-150 cells to perform a colony formation assay and found that the overexpression of FMR1-AS1 markedly increased the colony formation ability of ESCC cells (Additional file 6: Figure S3e, $\mathrm{f}$ and Additional file 4).

To probe the effects of FMR1-AS1 on cancer cell dynamics in vivo, we injected FMR1-AS1-upregulated cells, FMR1-AS1-downregulated cells and control cells into the hind flanks of nude mice. We observed that compared with control xenografts, the growth of the FMR1-AS1-upregulated xenografts was significantly promoted, whereas the growth of the FMR1-AS1-knockdown xenografts was substantially decreased (Fig. 3e). We also categorized 32 ESCC tissues according to the Ki67 expression ( $\geq 30 \%$, strong staining; $<30 \%$, weak staining) and found that the expression of FMR1-AS1 was much higher in the group of Ki67 strong staining than the group of weak Ki67 (Fig. 3f). Furthermore,
Ki67 immunostaining also showed more proliferation in xenograft tumors of the FMR1-AS1-upregulated ESCC cells, while TUNEL staining showed more apoptosis in FMR1-AS1-downregulated ESCC xenograft (Fig. 3g, h).

\section{Exosome transmitted FMR1-AS1 promotes c-Myc expression through interacting with TLR7 and activating NFKB signaling}

To search for the potential interacting molecules of FMR1-AS1 to regulate target genes at distal genomic loci, we purified endogenous FMR1-AS1 complexes using modified ChIRP [25] that allows unbiased high-throughput discovery of FMR1-AS1 associated proteins (Fig. 4a). We designed 16 probes (even/odd group) against human FMR1-AS1 RNA (Additional file 7: Table S2). In female ESCC cell line (ECA-109), we confirmed that FMR1-AS1 was completely solubilized by sonication and that over $75 \%$ of FMR1-AS1 RNA was selectively retrieved without enrichment of housekeeping GAPDH 


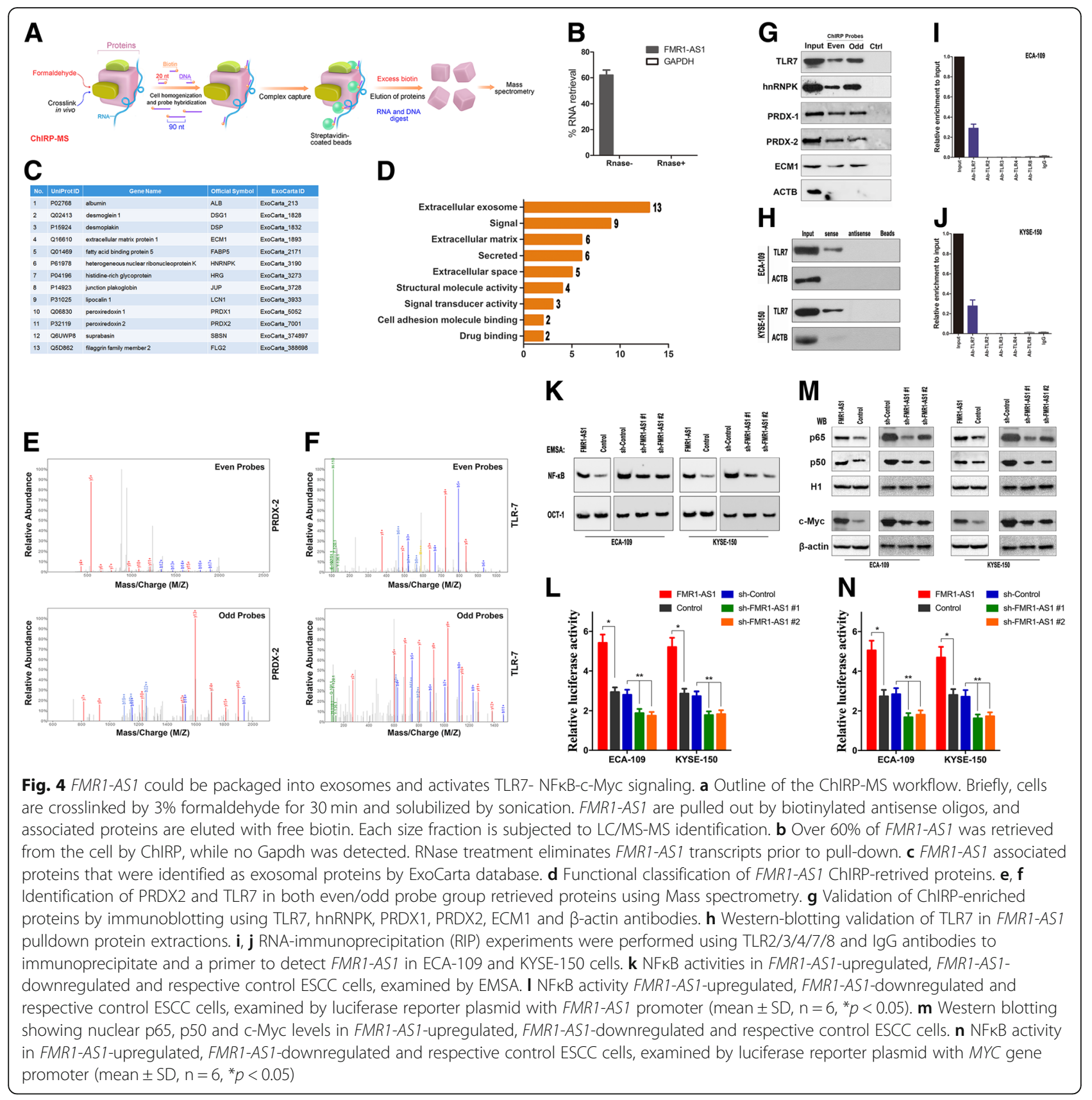

mRNA (Fig. 4b). There are 24 proteins both even and odd probes retrieved, among which 13 proteins are recorded as extracellular exosome components in DAVID and Exocarta database (Fig. 4c, d, Additional file 8: Table S3), indicating FMR1-AS1 which may be specifically sorted into exosomes. Specific FMR1-AS1 retrieved proteins identified by LC-MS/MS (Fig. 4e, f) was validated by ChIRP-western (Fig. 4g).

Among all the ChIRP-retrieved proteins, Toll-like receptor 7 (TLR7) came into notice. TLR7 is a pattern-specific immune receptor and localizes to the endosomal compartment. It is activated by antiviral compounds, viral RNA, single-stranded oligoribonucleotides and short interfering RNAs [26-28]. Further consistent with FMR1-AS1 ChIRP-MS data, a strong signal for TLR7 could be detected in the proteins that were pulled-down with the sense strand of FMR1-AS1 (Fig. 4h). To further confirm this interaction, we examined this interaction between FMR1-AS1 and TLR7 by RNA immunoprecipitation (RNA-IP). The results showed a significant enrichment of FMR1-AS1 bound to TLR7, compared with the non-specific IgG control (Fig. 4i, j). Taken together, these results demonstrated a specific association between TLR7 and FMR1-AS1. 
Exosomes are lipid-bilayer vesicles containing diverse proteins, RNAs, and DNAs [29, 30]. These contents have been shown to be recognized by multiple PRRs, including TLR7 [31-33]. However, the ability to stimulate TLR7 depended on GU-rich elements rather than on the exact GUUGUGU motif, as the motif analysis of previous studies have defined specific GU-rich 4-mer sequences like UUGU, GUUC, GUUU, UUUC, UGUU, or UCUC activating human TLR7 [34-36]. As expected, FMR1-AS1 contains 10 UUGU, 8 GUUC, 15 GUUU, 17 UUUC and 16 UGUU sites of these motif effectively engaged with TLR7.

In order to identify the associated biological processes and the corresponding signaling pathways of FMR1-AS1, we applied the gene set enrichment analysis (GSEA) to identify FMR1-AS1 associated gene sets and molecular signatures on the gene expression profiles (GSE70817) with FMR1-AS1 overexpressed and silenced [37]. The gene sets with significantly different levels of expression $(P<0.005)$ were picked up for GSEA. Interestingly, GSEA indicated that several classic stemness-associated signaling pathways, such as Wnt and Notch signaling, were significantly enriched in the cells with aberrantly expressed FMR1-AS1 (Additional file 9: Figure S4a and Additional file 4). The TOP-FLASH reporter and western-blotting suggested exogenous FMR1-AS1 in the ESCC cells induced Wnt and Notch signaling, but silencing FMR1-AS1 abolished this ability (Additional file 9: Figure S4b, c and Additional file 4). Moreover, GSEA results also indicated four putative $\mathrm{NFKB}_{\mathrm{K}}$ associated gene signatures that were significantly enriched in both FMR1-AS1 overexpressed and knocked-down cells (Additional file 9: Figure S3d and Additional file 4). The EMSA, luciferase reporter assays and western-blotting demonstrated that NFKB activity in ESCC cells was significantly increased by exogenous FMR1-AS1 and suppressed upon FMR1-AS1 silencing (Fig. 4k-m), strongly suggested that FMR1-AS1 is involved in NFKB activation. Among those Wnt and Notch signaling target genes, c-Myc is a well-known cancer stem factor, which also is under direct transcription regulation of NFkB [38]. Reasonably, c-Myc level was also increased by exogenous FMR1-AS1 and suppressed upon FMR1-AS1 silencing (Fig. $4 \mathrm{~m}, \mathrm{n}$ ). Our results of luciferase reporter assay with inhibition of $N F \kappa B$ also confirmed the transcription regulation role of $\mathrm{NF} \mathrm{B}$ on $\mathrm{c}-\mathrm{Myc}$ in human ESCC (Additional file 9: Figure $\mathrm{S} 4 \mathrm{e}$ and Additional file 4). Additionally, MYC also exhibit overexpression status in female ESCC patients based on TCGA and our sample data (Additional file 9: Figure S4f, g and Additional file 4).

\section{Intercellular transfer of FMR1-AS1 by exosomes disseminates ESCC stemness phenotypes}

We next investigated the existing pattern of exosomal FMR1-AS1. The levels of FMR1-AS1 in culture medium (CM) of the ESCC cells remained unchanged upon RNase treatment, but they were significantly decreased when treated with RNase and Triton X-100 simultaneously (Additional file 10: Figure S5a and Additional file 4). The result indicated that extracellular FMR1-AS1 was mainly wrapped by membrane instead of being directly released. The data from exoRbase also indicate FMR1-AS1 could be detected in human blood exosomes (Additional file 10: Figure S5b and Additional file 4). We then purified exosomes from ESCC cell CM and patients' blood serum and confirmed their existence by typical particle size and exosome markers CD63 and CD81 (Fig. 5a, b). As expected, the exosomal FMR1-AS1 levels were significantly higher in the FMR1-AS1 upregulated cells and were lower in the FMR1-AS1 downregulated cells than in the corresponding control cells respectively (Fig. 5c).

Cell-secreted exosomes and capped cargoes can be internalized by neighboring cells [30]. As expected, the intracellular levels of FMR1-AS1 were increased upon incubation with exosomes from the FMR1-AS1 overexpressed cells, but not the FMR1-AS1 knocked-down cells (Fig. 5d). Intriguingly, serum exosomal FMR1-AS1 expression levels were significantly higher in the female ESCC patients than in the healthy control subjects (Fig. 5e), as well as higher in ESCC recurrent patient group than in first visit group (Fig. 5f). We observed the consistency between FMR1-AS1 tumor expression and serum expression within individual ESCC patients (Fig. 5g). Moreover, we also determined the correlation between the serum levels of FMR1-AS1 and the overall survival (OS) of the female ESCC patients. We found that female patients from the discovery set (Suzhou: 146) in the high serum FMR1-AS1 subgroup had a lower OS than those in the low FMR1-AS1 subgroup (HR = $1.942 ; 95 \% \mathrm{CI}=1.246-3.027 ; P=0.0029)$. And this result was confirmed in the validation set (Guangzhou: 107, $\mathrm{HR}=1.784 ; 95 \% \mathrm{CI}=1.06-3.004 ; P=0.0163)$ and the pooled set $(\mathrm{HR}=1.761 ; 95 \% \mathrm{CI}=1.259-2.462 ; P=$ 0.0006), the high serum FMR1-AS1 group showed a lower OS of female ESCC patients (Fig. 5h). These results indicate a potential application of FMR1-AS1 as a biomarker of female ESCC.

The findings above rise the question that from where FMR1-AS1 exosomes derived. Since NFkB affected Wnt and Notch pathways play crucial roles in cancer stemness, we hypothesis that FMR1-AS1 exosomes derived from ESCC cancer stem-like cells. To address this hypothesis, we newly enrolled 12 female ESCC samples and used FACS to isolate the stem-like subpopulation with cell-surface marker CD44. Interestingly, the expression levels of FMR1-AS1, TSIX and c-Myc were significantly higher in the $\mathrm{CD}_{4} 4^{+}$(stem-like) ESCC 


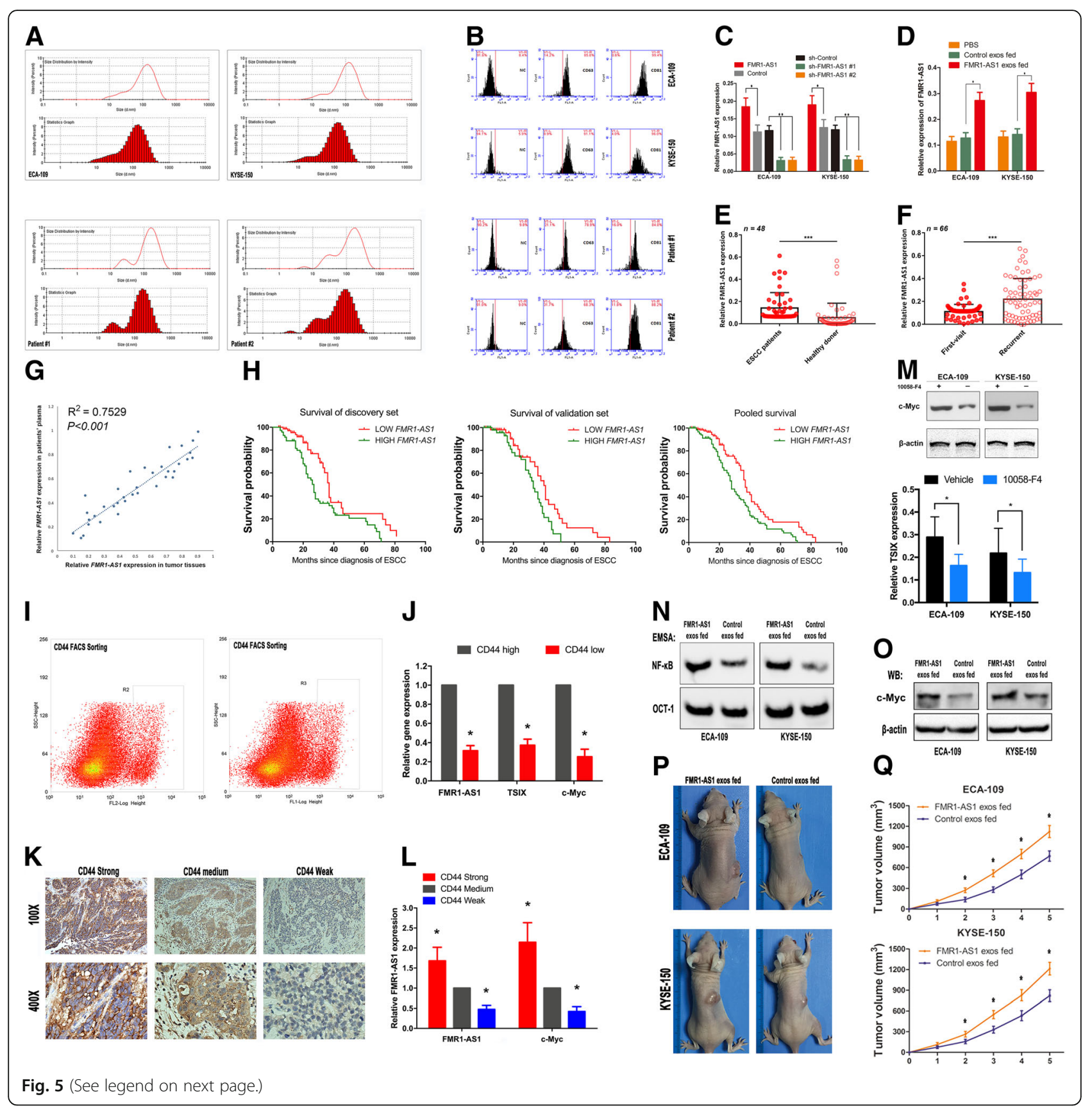




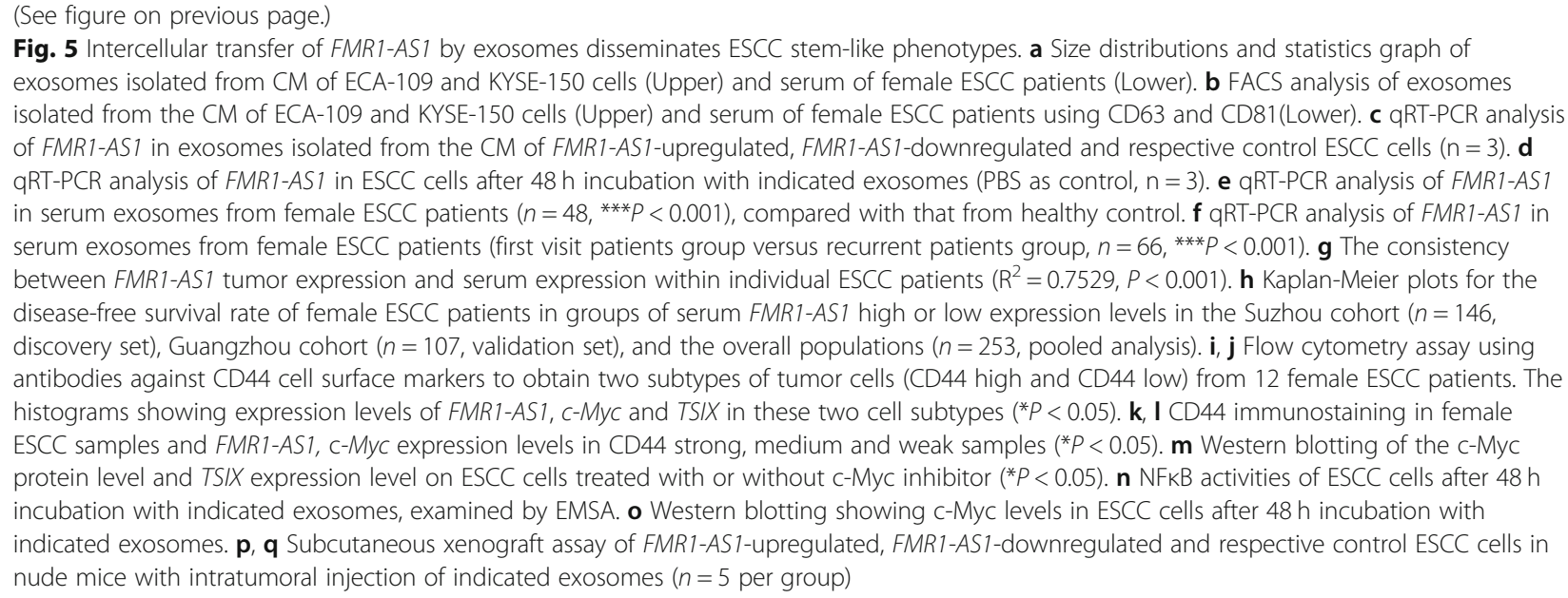

subpopulation cells than in the CD44- cells (Fig. 5i, j). Consistently, we categorized 32 ESCC tissues by the level of CD44 expression (strong $\geq 50 \%$; 50\% > medium $\geq 20 \%$; weak $<20 \%$ ) and FMR1-AS1 and c-Myc were both observed much higher expression in the CD44 strong staining tissues than in the CD44 medium and weak samples (Fig. 5k, l).

Since the acquisition of pluripotency always accompanied by the regulation of TSIX, and c-Myc was found to be one of the activators of TSIX [39]. We then investigated the regulation role of c-Myc on TSIX in ESCC cells using $\mathrm{c}-\mathrm{Myc}$ inhibitor. The results showed that c-Myc could also associated with TSIX promoter and activate TSIX expression in ESCC cells (Fig. $5 \mathrm{~m}$ ).

To further confirm that FMR1-AS1 could be transferred to recipient cells via exosomes, conferring functions and phenotypes to recipient ESCC cells, we first determined the NFkB transcriptional activity in ESCC cells incubated directly with exosomes from the FMR1-AS1 overexpressed cells. The results of luciferase reporter assay and EMSA showed that NFkB transcriptional activity was significantly increased after incubation with exosomes from the FMR1-AS1 overexpressed cells (Fig. 5n, Additional file 10: Figure S5c and Additional file 4). And qPCR and western-blotting upon exosome incubation showed that, accompanied by NFkB activation, c-Myclevel was also upregulated (Fig. 5o, Additional file 10: Figure S5d and Additional file 4). Then to demonstrate the effect of exosomal FMR1-AS1 on ESCC phenotypes in vivo, we administered exosomes derived from the $F M R 1-A S 1$ overexpressed and control cells intratumorally into ECA-109 and KYSE-150 xenografts. Exosomes derived from the FMR1-AS1 overexpressed cells significantly induced the growth of ESCC xenografts in female mice (Fig. 5p, q). Furthermore, Wnt and Notch signaling were also induced after incubation with exosomes from the FMR1-AS1 overexpressed cells, compared to exosomes from the control cells (Additional file 10: Figure S5e, f and Additional file 4). Collectively, these findings demonstrated that exosomes from the FMR1-AS1 overexpressed cells could endow the basal cells with stem-like phenotypes via intercellular transfer of FMR1-AS1, through activating NFKB-dependent pathways, thus contributing to ESCC intratumorally stemness dynamic transition.

\section{TLR7-NFKB-c-Myc signaling pathway activation is responsible for FMR1-AS1-mediated reprogramming of ESCC cells}

We further sought to identify the underlying mechanism of FMR1-AS-mediated transition of ESCC stem-like phenotypes. Inspired by the results above, we focused on TLR7-MyD88-NFkB signaling pathway. Therefore, by stably silencing TLR7 in ESCC cells, we found that the inhibition of TLR7 could block the activation of NFkB-c-Myc signaling pathway and suppressed the xenografts growth phenotypes by FMR1-AS1 exosome incubation (Fig. 6a-c, Additional file 11: Figure S6a and Additional file 4). Moreover, the silencing of $M y D 88$ could also hinder the NFкB-c-Myc signaling cascades and phenotype transition through FMR1-AS1 exosome incubation in the ESCC cells (Fig. 6d-f, Additional file 11: Figure S6b and Additional file 4). Moreover, we systemically investigated the effect of transmitted FMR1-AS1 in vivo using xenograft model. We subcutaneously co-injected two types of cell mixture (ECA-109_luc \& ECA-109_FMR1-AS1 and KYSE-150_luc \& KYSE-150 FMR1-AS1; cell number ratio $=1: 5$ ). Bioluminescent imaging revealed that the xenografts growth ability of the cell mixture containing 1/5 FMR1-AS1 overexpressed cells were notably stronger than the control cell mixture (Fig. 6g), indicating exosomal FMR1-AS1 could induce ESCC tumor growth in vivo. Together, these results suggest that exosomal FMR1-AS1 induces ESCC cancer stem-like phenotypes by activating TLR7-NFkB signaling pathway, thus promoting c-Myc expression level. 


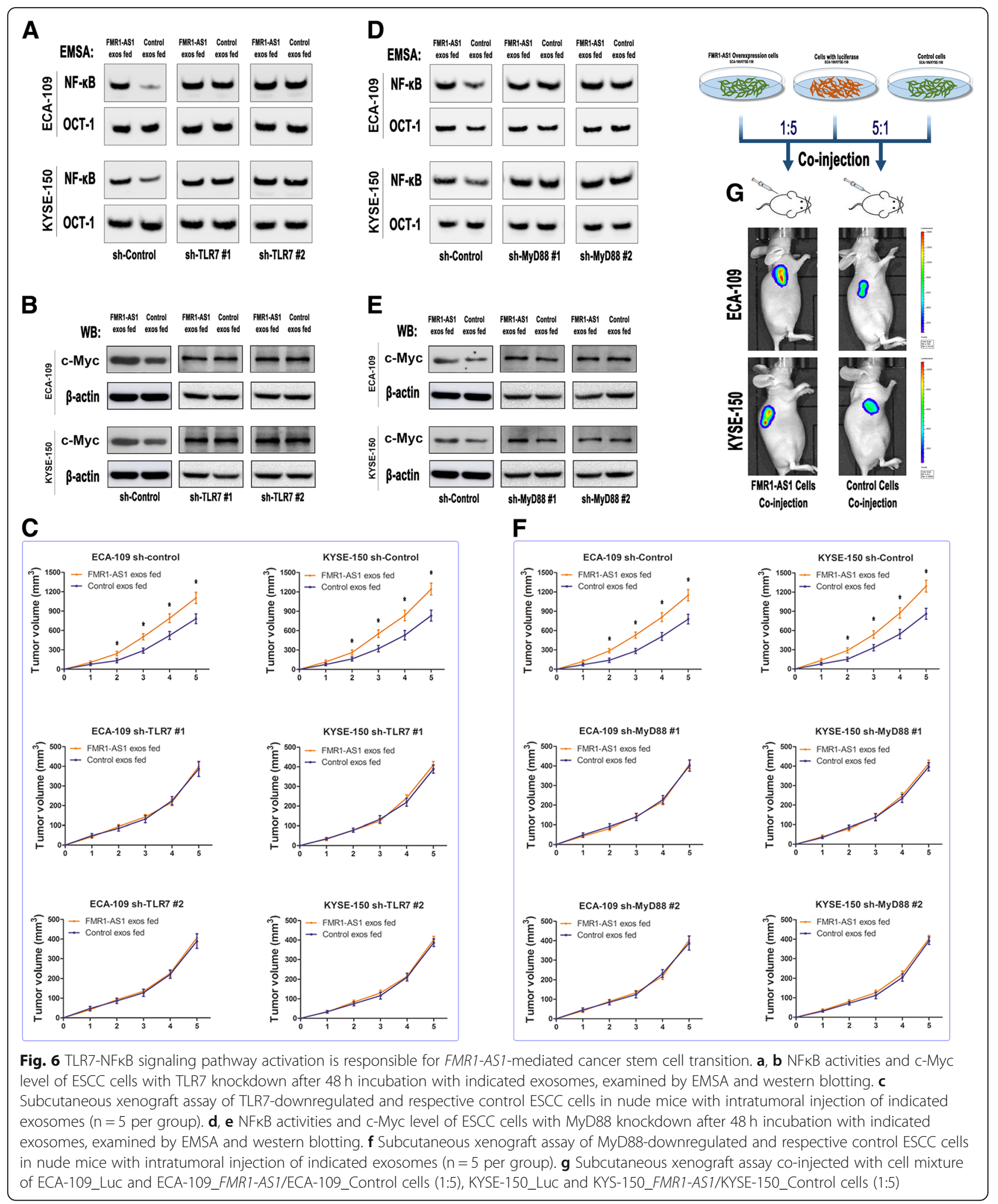

\section{Discussion}

Globally, there is a large male predominance in both esophageal squamous and adenocarcinoma. The gender difference in cancer susceptibility is one of the most consistent findings in cancer epidemiology and can give important clues for the etiology of cancers and should be examined in all genetic and non-genetic association studies. Although the incidence rate of ESCC among 


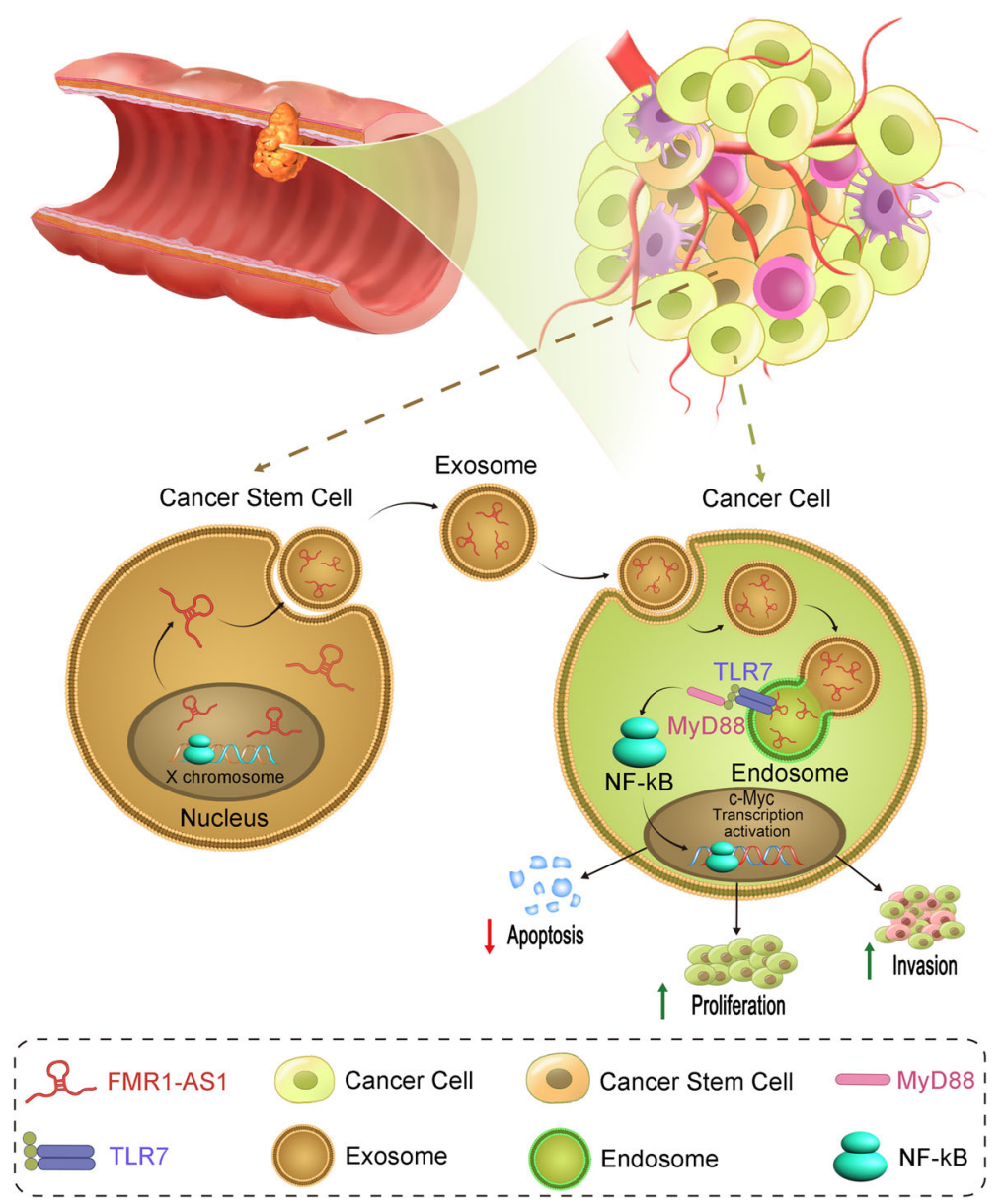

Fig. 7 A schematic diagram of FMR1-AS1 mediated TLR7-NFKB signaling activation between cancer stem-like cells and cancer cells of female ESCC

females is much lower than that among males, female ESCC may have specific pathogenic factors, either genetic or environmental. In this study, we identified the X-linked lncRNA, FMR1-AS1, which differentially expressed in female ESCC patients, as a potential female-specific genetic factor that contribute to female ESCC.

Using a large cohort of ESCC microarrays, we discovered a female specific aberrantly expressed lncRNA, FMR1-AS1. It is a primate-specific noncoding RNA transcript $(2.4 \mathrm{~kb})$ that resides upstream and shares a bidirectional promoter with FMR1. The CGG expansion in the 5' UTR of FMR1 appears not only affected on the transcription of FMR1-AS1 and FMR1, but also associated with sXCI [40]. However, sXCI has been found mainly in female adults, and it is linked to the development of breast cancer [41], ovarian cancer [42] and esophageal carcinoma [24]. In the present study, we found that FMR1-AS1 expression was more prevalent in the patients with a larger sXCI ratio, suggesting sXCI may be a risk factor associated with FMR1-AS1 expression and that sXCI could influence the development of female ESCC. This may be another factor that contributes to the gender difference in human ESCC incidence. Our data and previous reports have demonstrated that FMR1-AS1 greatly affected female ESCC cell proliferation and survival both in vitro and in vivo. Meanwhile, it is well known that the reprogramming of $\mathrm{X}$-inactivation during acquisition of pluripotency is accompanied by the repression of XIST, the trigger of X-inactivation, and the upregulation of its antisense counterpart TSIX. Our data demonstrated that TSIX showed some correlation with FMR1-AS1 and overexpressed in CD44 $4^{\text {high }}$ ESCC cells and samples, indicating that sXCI within ESCC development may tend to the FMR1-AS1 highly expressed cells to contribute female ESCC tumorigenesis and malignancy.

In the case of interconversion between CSCs and non-CSCs, exosomes may be taken granted as important signaling information transmitter by transferring 
stemness-related molecules to non-CSCs, which lead non-CSCs to regain stemness phenotype. Our data of ChIRP-MS and followed-up experiments indicate that FMR1-AS1 could be selectively packaged into exosomes derived from ESCC CSCs. Cancer cells could recruit and alter phenotypic and functional attributes by uptaking exosomes. Those specific cargo molecules are needed for tumor growth, metastasis and drug resistance to enhance tumorigenicity or stemness phenotype of cancer cells. Also, our data demonstrated that FMR1-AS1 could interact with the Toll-like Receptor 7, TLR7. TLR7 was identified as one of the PRRs-sensing exosomes that contribute to the stimulation of downstream pathways in breast cancer cells [31]. Intriguingly, TLR7 documented as a member of endosomal TLRs. And gender difference in TLR7 response has been reported previously in human immune diseases [43, 44]. Our study also showed that sXCI may contribute to the FMR1-AS1-dependent TLR7 responses in female ESCC cells. Further, recent studies have shown that TLRs are expressed in a variety of tumor cells through the MyD88 pathway to ultimately activate $\mathrm{NF \kappa B}$, stimulating stem cell associated factors and pathways, especially c-Myc within Wnt and Notch signaling [45-47]. c-Myc is also among the several stemness factors that could direct promote TSIX expression [48]. Previous research has examined the contribution of exosomes to cancer population equilibrium and tumor heterogeneity, in which transitions between clonogenic states could be modulated by exosome-mediated Wnt signaling [49]. Our results showed that FMR1-AS1 notably overexpressed in the $\mathrm{CD} 44^{+}$cancer stem-like cells within female ESCC patients. Transfer of FMR1-AS1 or FMR1-AS1 overexpressed ESCC cell derived exosomes to wild-type ESCC cell resulted in aggressive phenotypes, including elevated proliferation, anti-apoptosis, migration and invasion ability. And these responses were abolished in MyD88 or TLR7 deficient cells suggesting that exosomes containing FMR1-AS1 derived from ESCC CSCs could activate TLR7-MyD88-NFkB-c-Myc signaling pathways in non-CSCs involved with stemness phenotypes while the release and uptake of exosome could be controlled. In general, several reports and our findings together indicate that exosomes derived from aggressive cancer cells, especially the CSCs could transport oncogenic factors, including lncRNAs, to recipient cells within tumor microenvironment to induce tumor aggression and progression.

In sum, the sex-dependent FMR1-AS1 within exosomes secreted by ESCC cancer stem-like cells can bind to endosomal TLR7 and activate TLR7-NFkB signaling, thus promoting the expression of downstream CSC-linked gene, c-Myc, in the recipient non-CSCs (Fig. 7). This mechanism of FMR1-AS1 is implicated in tumor intrinsic communication and contribute to ESCC development.

\section{Conclusions}

Overall, our study could, to some extent, broaden the understanding of the complex processes of tumor cell heterogeneity and highlight exosomes as a key player in this process, in which case a comprehensive therapeutic strategy targeting exosomes to eradicate CSCs for cancer therapeutics would be more effective.

\section{Additional files}

Additional file 1: Table S1. Distributions of characteristics among female
ESCC patients in Chinese populations used for study. (DOCX $18 \mathrm{~kb}$ )

Additional file 2: Materials and Methods. (DOCX $34 \mathrm{~kb}$ )

Additional file 3: Figure S1. Female specific $X$-associated IncRNA screening and FMR1-AS1 expression patterns in female ESCC samples and cells. (TIF $339 \mathrm{~kb}$ )

Additional file 4: Supplementary figure legends. (DOCX $17 \mathrm{~kb}$ ) Additional file 5: Figure S2. Biological characterization of FMR1-AS1. (TIF 7610 kb)

Additional file 6: Figure S3. Effects of ectopic FMR1-AS1 expression on female ESCC cells. (TIF $5856 \mathrm{~kb}$ )

Additional file 7: Table S2. Information of primers and probes. (XLSX $15 \mathrm{~kb}$ )

Additional file 8: Table S3. Results of mass spectrum. (XLSX $23 \mathrm{~kb}$ ) Additional file 9: Figure S4. FMR1-AS1 could be packaged into exosomes and activates TLR7- NFKB-c-Myc signaling. (TIF 1679 kb)

Additional file 10: Figure S5. Intercellular transfer of FMR1-AS1 by exosomes disseminates ESCC stem-like phenotypes. (TIF $1036 \mathrm{~kb}$ )

Additional file 11: Figure S6. TLR7-NFKB signaling pathway activation is responsible for FMR1-AS1-mediated cancer stem cell transition. (TIF 4009 kb)

\section{Abbreviations}

CICs: Cancer-initiating cells; CR: Corrected ratio; CSCs: Cancer stem cells; ESCC: Esophageal squamous cell carcinoma; LncRNA: Long non-coding RNA; PRRs: Pattern recognition receptors; TFBS: Transcription factor binding sites; TLR7: Toll-like receptor 7

\section{Acknowledgments}

We thank all individuals who take part in this research.

\section{Funding}

This work was supported by the National Scientific Foundation of China grants 81772544 and 81472630; Science Foundation for Distinguished Young Scholars in Jiangsu (BK20160008); A Project Funded by the Priority Academic Program Development of Jiangsu Higher Education Institutions; National Key R\&D Program of China (2016YFC1302100); the Program for Guangdong Introducing Innovative and Entrepreneurial Teams (2017ZT07S096).

Availability of data and materials

Please contact the corresponding author for all data requests.

\section{Authors' contributions}

YZ and WL: study concept and design, analysis and interpretation of data, drafting of the manuscript, statistical analysis, obtained funding, study supervision. WL, LZ, BG, SW, JD and JL: study concept and design, acquisition of data, analysis and interpretation of data, drafting of the manuscript, statistical analysis. BG and YW: acquisition of data. All authors read and approved the final manuscript.

Ethics approval and consent to participate

The Medical Ethics Committees of Soochow University and Guangzhou Medical College approved this study. 


\section{Consent for publication}

Not applicable.

\section{Competing interests}

The authors declare that they have no competing interests.

\section{Publisher's Note}

Springer Nature remains neutral with regard to jurisdictional claims in published maps and institutional affiliations.

\section{Author details}

'Department of Genetics, Medical College of Soochow University, Suzhou 215123, China. ${ }^{2}$ Department of Radiotherapy \& Oncology, The Second Affiliated Hospital of Soochow University, San Xiang Road No. 1055, Suzhou 215004, China. ${ }^{3}$ The Institute for Chemical Carcinogenesis, The State Key Lab of Respiratory Disease, Guangzhou Medical University, Guangzhou 510182, China.

Received: 5 November 2018 Accepted: 28 January 2019

Published online: 08 February 2019

\section{References}

1. Jemal A, Bray F, Center MM, Ferlay J, Ward E, Forman D. Global cancer statistics. CA Cancer J Clin. 2011;61:69-90.

2. Li W, Zheng J, Deng J, You Y, Wu H, Li N, Lu J, Zhou Y. Increased levels of the long intergenic non-protein coding RNA POU3F3 promote DNA methylation in esophageal squamous cell carcinoma cells. Gastroenterol. 2014;146:1714-1726 e1715.

3. Karreth FA, Tay Y, Perna D, Ala U, Tan SM, Rust AG, DeNicola G, Webster KA, Weiss D, Perez-Mancera PA, et al. In vivo identification of tumorsuppressive PTEN ceRNAs in an oncogenic BRAF-induced mouse model of melanoma. Cell. 2011;147:382-95.

4. Prensner JR, lyer MK, Sahu A, Asangani IA, Cao Q, Patel L, Vergara IA, Davicioni E, Erho N, Ghadessi M, et al. The long noncoding RNA SChLAP1 promotes aggressive prostate cancer and antagonizes the SWI/SNF complex. Nat Genet. 2013:45:1392-8.

5. Huarte M, Guttman M, Feldser D, Garber M, Koziol MJ, Kenzelmann-Broz D, Khalil AM, Zuk O, Amit I, Rabani M, et al. A large intergenic noncoding RNA induced by p53 mediates global gene repression in the p53 response. Cell. 2010;142:409-19.

6. Gupta RA, Shah N, Wang KC, Kim J, Horlings HM, Wong DJ, Tsai MC, Hung $T$, Argani $P$, Rinn JL, et al. Long non-coding RNA HOTAIR reprograms chromatin state to promote cancer metastasis. Nature. 2010:464:1071-6.

7. Hung $C L$, Wang $L Y, Y u$ YL, Chen HW, Srivastava S, Petrovics G, Kung HJ. A long noncoding RNA connects c-Myc to tumor metabolism. Proc Natl Acad Sci U S A. 2014;111:18697-702.

8. Tkach $\mathrm{M}$, Thery $\mathrm{C}$. Communication by extracellular vesicles: where we are and where we need to go. Cell. 2016;164:1226-32.

9. Valenti $R$, Huber $V$, lero M, Filipazzi P, Parmiani G, Rivoltini L. Tumor-released microvesicles as vehicles of immunosuppression. Cancer Res. 2007;67:2912-5.

10. Qu L, Ding J, Chen C, Wu ZJ, Liu B, Gao Y, Chen W, Liu F, Sun W, Li XF, et al. Exosome-transmitted IncARSR promotes Sunitinib resistance in renal Cancer by acting as a competing endogenous RNA. Cancer Cell. 2016;29:653-68.

11. Gezer U, Ozgur E, Cetinkaya M, Isin M, Dalay N. Long non-coding RNAs with low expression levels in cells are enriched in secreted exosomes. Cell Biol Int. 2014:38:1076-9.

12. Sun $Z$, Wang $L$, Dong $L$, Wang $X$. Emerging role of exosome signalling in maintaining cancer stem cell dynamic equilibrium. J Cell Mol Med. 2018: 22(8);3719-28

13. Poleszczuk J, Enderling H. Cancer stem cell plasticity as tumor growth promoter and catalyst of population collapse. Stem Cells Int. 2016;2016: 3923527.

14. Cabrera MC, Hollingsworth RE, Hurt EM. Cancer stem cell plasticity and tumor hierarchy. World J Stem Cells. 2015;7:27-36.

15. Dragomir M, Chen B, Calin GA. Exosomal IncRNAs as new players in cell-tocell communication. Transl Cancer Res. 2018;7:S243-52.

16. Xu J, Liao K, Zhou W. Exosomes regulate the transformation of cancer cells in cancer stem cell homeostasis. Stem Cells Int. 2018;2018:4837370.

17. Steinbichler TB, Dudas J, Riechelmann H, Skvortsova II. The role of exosomes in cancer metastasis. Semin Cancer Biol. 2017:44:170-81.
18. Jin $H$, Wu Y, Tan $X$. The role of pancreatic cancer-derived exosomes in cancer progress and their potential application as biomarkers. Clin Transl Oncol. 2017;19:921-30.

19. Fanini F, Fabbri M. Cancer-derived exosomic microRNAs shape the immune system within the tumor microenvironment: state of the art. Semin Cell Dev Biol. 2017:67:23-8.

20. Chu C, Chang HY. Understanding RNA-chromatin interactions using chromatin isolation by RNA purification (ChIRP). Methods Mol Biol. 2016; 1480:115-23.

21. Khalil AM, Faghihi MA, Modarresi F, Brothers SP, Wahlestedt C. A novel RNA transcript with antiapoptotic function is silenced in fragile $X$ syndrome. PLoS One. 2008;3:e1486.

22. Lanni S, Goracci M, Borrelli L, Mancano G, Chiurazzi P, Moscato U, Ferre F, Helmer-Citterich M, Tabolacci E, Neri G. Role of CTCF protein in regulating FMR1 locus transcription. PLoS Genet. 2013:9:e1003601.

23. Barad DH, Darmon S, Weghofer A, Latham GJ, Filipovic S, Wang Q, Kushnir VA, Albertini DF, Gleicher N. Association of skewed X-chromosome inactivation with FMR1 CGG repeat length and anti-Mullerian hormone levels: a cohort study. Reprod Biol Endocrinol. 2017:15:34.

24. Li G, Jin T, Liang H, Tu Y, Zhang W, Gong L, Su Q, Gao G. Skewed Xchromosome inactivation in patients with esophageal carcinoma. Diagn Pathol. 2013;8:55.

25. Chu C, Zhang QC, da Rocha ST, Flynn RA, Bharadwaj M, Calabrese JM, Magnuson T, Heard E, Chang HY. Systematic discovery of Xist RNA binding proteins. Cell. 2015;161:404-16.

26. Heil F, Hemmi H, Hochrein H, Ampenberger F, Kirschning C, Akira S, Lipford $\mathrm{G}$, Wagner $\mathrm{H}$, Bauer S. Species-specific recognition of single-stranded RNA via toll-like receptor 7 and 8. Science. 2004:303:1526-9.

27. Diebold SS, Kaisho T, Hemmi H, Akira S, Reis e Sousa C. Innate antiviral responses by means of TLR7-mediated recognition of single-stranded RNA. Science. 2004;303:1529-31.

28. Hornung V, Guenthner-Biller M, Bourquin C, Ablasser A, Schlee M, Uematsu S, Noronha A, Manoharan M, Akira S, de Fougerolles A, et al. Sequence-specific potent induction of IFN-alpha by short interfering RNA in plasmacytoid dendritic cells through TLR7. Nat Med. 2005;11: 263-70.

29. Liu Y, Gu Y, Cao X. The exosomes in tumor immunity. Oncoimmunology. 2015:4:e1027472.

30. Melo SA, Sugimoto H, O'Connell JT, Kato N, Villanueva A, Vidal A, Qiu L, Vitkin E, Perelman LT, Melo CA, et al. Cancer exosomes perform cellindependent microRNA biogenesis and promote tumorigenesis. Cancer Cell. 2014;26:707-21.

31. Boelens MC, Wu TJ, Nabet BY, Xu B, Qiu Y, Yoon T, Azzam DJ, Twyman-Saint Victor C, Wiemann BZ, Ishwaran $\mathrm{H}$, et al. Exosome transfer from stromal to breast cancer cells regulates therapy resistance pathways. Cell. 2014;159:499-513.

32. Chow A, Zhou W, Liu L, Fong MY, Champer J, Van Haute D, Chin AR, Ren X, Gugiu BG, Meng Z, et al. Macrophage immunomodulation by breast cancerderived exosomes requires toll-like receptor 2-mediated activation of NFkappaB. Sci Rep. 2014:4:5750.

33. Lehmann SM, Kruger C, Park B, Derkow K, Rosenberger K, Baumgart J, Trimbuch T, Eom G, Hinz M, Kaul D, et al. An unconventional role for miRNA: let-7 activates toll-like receptor 7 and causes neurodegeneration. Nat Neurosci. 2012:15:827-35.

34. Forsbach A, Nemorin JG, Montino C, Muller C, Samulowitz U, Vicari AP, Jurk M, Mutwiri GK, Krieg AM, Lipford GB, Vollmer J, Identification of RNA sequence motifs stimulating sequence-specific TLR8-dependent immune responses. J Immunol. 2008;180:3729-38.

35. Fabbri M, Paone A, Calore F, Galli R, Gaudio E, Santhanam R, Lovat F, Fadda P, Mao C, Nuovo GJ, et al. MicroRNAs bind to toll-like receptors to induce prometastatic inflammatory response. Proc Natl Acad Sci U S A. 2012;109:E2110-6.

36. Tudor S, Giza DE, Lin HY, Fabris L, Yoshiaki K, D'Abundo L, Toale KM, Shimizu M, Ferracin M, Challagundla KB, et al. Cellular and Kaposi's sarcomaassociated herpes virus microRNAs in sepsis and surgical trauma. Cell Death Dis. 2014:5:e1559

37. Peschansky VJ, Pastori C, Zeier Z, Motti D, Wentzel K, Velmeshev D, Magistri M, Bixby JL, Lemmon VP, Silva JP. Wahlestedt C. Changes in expression of the long non-coding RNA FMR4 associate with altered gene expression during differentiation of human neural precursor cells. Front Genet. 2015:6:263.

38. La Rosa FA, Pierce JW, Sonenshein GE. Differential regulation of the c-myc oncogene promoter by the NF-kappa B rel family of transcription factors. Mol Cell Biol. 1994;14:1039-44. 
39. Navarro P, Oldfield A, Legoupi J, Festuccia N, Dubois A, Attia M, Schoorlemmer J, Rougeulle C, Chambers I, Avner P. Molecular coupling of Tsix regulation and pluripotency. Nature. 2010;468:457-60.

40. Heine-Suner D, Torres-Juan L, Morla M, Busquets X, Barcelo F, Pico G, Bonilla L, Govea N, Bernues M, Rosell J. Fragile-X syndrome and skewed X-chromosome inactivation within a family: a female member with complete inactivation of the functional X chromosome. Am J Med Genet A. 2003;122A:108-14.

41. Kristiansen M, Langerod A, Knudsen GP, Weber BL, Borresen-Dale AL, Orstavik $\mathrm{KH}$. High frequency of skewed $\mathrm{X}$ inactivation in young breast cancer patients. J Med Genet. 2002;39:30-3.

42. Buller RE, Sood AK, Lallas T, Buekers T, Skilling JS. Association between nonrandom X-chromosome inactivation and BRCA1 mutation in germline DNA of patients with ovarian cancer. J Natl Cancer Inst. 1999:91:339-46.

43. Berghofer B, Frommer T, Haley G, Fink L, Bein G, Hackstein H. TLR7 ligands induce higher IFN-alpha production in females. J Immunol. 2006;177:2088-96.

44. Meier A, Chang JJ, Chan ES, Pollard RB, Sidhu HK, Kulkarni S, Wen TF, Lindsay RJ, Orellana L, Mildvan D, et al. Sex differences in the toll-like receptor-mediated response of plasmacytoid dendritic cells to HIV-1. Nat Med. 2009;15:955-9.

45. Garner JM, Fan M, Yang CH, Du Z, Sims M, Davidoff AM, Pfeffer LM. Constitutive activation of signal transducer and activator of transcription 3 (STAT3) and nuclear factor kappaB signaling in glioblastoma cancer stem cells regulates the notch pathway. J Biol Chem. 2013;288:26167-76.

46. Chefetz I, Alvero AB, Holmberg JC, Lebowitz N, Craveiro V, Yang-Hartwich Y, Yin G, Squillace L, Gurrea Soteras M, Aldo P, Mor G. TLR2 enhances ovarian cancer stem cell self-renewal and promotes tumor repair and recurrence. Cell Cycle. 2013;12:511-21.

47. Yamamoto M, Taguchi Y, Ito-Kureha T, Semba K, Yamaguchi N, Inoue J. NFkappaB non-cell-autonomously regulates cancer stem cell populations in the basal-like breast cancer subtype. Nat Commun. 2013;4:2299.

48. Gayen S, Maclary E, Buttigieg E, Hinten M, Kalantry S. A primary role for the Tsix IncRNA in maintaining random X-chromosome inactivation. Cell Rep. 2015;11:1251-65.

49. Koch R, Demant M, Aung T, Diering N, Cicholas A, Chapuy B, Wenzel D, Lahmann M, Guntsch A, Kiecke C, et al. Populational equilibrium through exosome-mediated Wnt signaling in tumor progression of diffuse large Bcell lymphoma. Blood. 2014;123:2189-98.

Ready to submit your research? Choose BMC and benefit from:

- fast, convenient online submission

- thorough peer review by experienced researchers in your field

- rapid publication on acceptance

- support for research data, including large and complex data types

- gold Open Access which fosters wider collaboration and increased citations

- maximum visibility for your research: over $100 \mathrm{M}$ website views per year

At $\mathrm{BMC}$, research is always in progress.

Learn more biomedcentral.com/submissions 